\title{
Prevalence of anemia and its etiology: a study in a semi urban area
}

\author{
Yeluri SK ${ }^{1}$ \\ ${ }^{1}$ Dr Sailendra Kumar Yeluri, Assistant Professor, Department of Pediatrics, Mallareddy Institute of Medical Sciences, \\ Venkatarama Colony, Suraram, Hyderabad, Telangana, India
}

Address for Correspondence: Email: yeluri_sailu@yahoo.com

\begin{abstract}
Introduction: Anemia is recognized as a public health problem throughout the world affecting both developed and developing countries and is associated with nutritional deficiencies especially due to iron deficiency, which is the main factor for microcytic anemia, while folate or Vitamin B12 deficiencies are known to be responsible for macrocytic anemia. This study was conducted to estimate the prevalence of anemia in our area and its association with the lack nutrients. Materials and Methods: General demographic details such as age, gender, weight, economic status of the parents, etc were taken for 392 children between the ages of 6 months to 5 years. Blood samples were taken for all the patients for hemoglobin levels and estimation of iron, folic acid and Vitamin B12. Results: 179 (45.7\%) patients were found to be anemic. Of them, $91(50.8 \%)$ were with mild anemia, $76(44.1 \%)$ were with moderate anemia. Severe anemia accounted for only $9(5.0 \%)$ of the cases. Out of patients, the most prevalent age group with anemia was found to be 12$<24$ months, followed by $6-<12$ months. Of the micronutrients testes, iron deficiency either pure or mixed with other nutrients was the most predominant with folic acid deficiency being the lowest. Conclusion: Proper food, rich in nutrients, iron supplements are some of the essential requirements with regular check ups for the children below 5 years. Education regarding the importance of nutrition and harmful effects of iron deficiency on the child must be given.
\end{abstract}

Keywords: Anemia, Children, Prevalence, Etiology, Iron deficiency, Malnutrition

\section{Introduction}

Anemia is recognized as a public health problem throughout the world affecting both developed and developing countries. It is estimated that about $30 \%$ of the world's population is anemic and about $36 \%$ of the children between 6-12 years are said to have anemia $[1,2]$. Among the developing countries, the estimate of prevalence is $77 \%[3,4]$. Anemia among the 5-14 year olds have been found to be around $66.7-77 \%$ in some studies $[3,5]$. The prevalence in the sub-Saharan Africa was reported to be $43 \%-74 \%[6,7]$.

In the developed world, the rate of anemia among the Americans was very high among the children with 50\% of them being affected in Mexico and between 45-70\% in Equador $[8,9,10]$. The prevalence is $30-60 \%$ in Brazil, with $45 \%$ of children below 5 years being affected [11]. Most anemia cases are associated with nutritional deficiencies especially due to iron deficiency, which is the main factor for microcytic

Manuscript received: $08^{\text {th }}$ March 2016

Reviewed: $15^{\text {th }}$ March 2016

Author Corrected; 26 th March 2016

Accepted for Publication: 04 $4^{\text {th }}$ April 2016 anemia, while folate or Vitamin B12 deficiencies are known to be responsible for macrocytic anemia [12,13]. Many parasitic infections like malaria are also known to be associated with anemia $[6,7,13]$. Normally anemia occurs in childhood due to bad eating habits and this is further accentuated by the weaning period [14]. This could be because the mother's milk is replaced by other food which is not as nutritious and lacks in nutrients such as iron, folic acid and Vitamin B12 [15,16].

This study was conducted to estimate the prevalence of anemia in our area and the lack nutrients that leads to it.

\section{Materials and Methods}

This study was conducted by the department of pediatrics at Mallareddy Institute of Medical Sciences. 392 children between the ages of 6 months to 5 years who came to our department were included in the study. This study was performed after attaining the clearance by the institutional ethical committee. 
General demographic details such as age, gender, weight, economic status of the parents, etc were taken for all the patients. Blood samples were taken for all the patients to check the hemoglobin levels of them and to estimate the levels of iron, folic acid and Vitamin B12. Detailed history and thorough physical and clinical examination was done. The WHO criterion (hemoglobin $<11 \mathrm{~g} / \mathrm{dL}$ ) was used to diagnose anemia [8].

\section{Results}

Out of the 392 children recruited into the study, there were $233(59.4 \%)$ were males and 169(43.1\%) were females. 179 (45.7\%) patients out of the 392 children were found to be anemic. Of them, 91 (50.8\%) were with mild anemia, 76 (44.1\%) were with moderate anemia. Severe anemia accounted for only $9(5.0 \%)$ of the cases. (Fig: 1$)$.

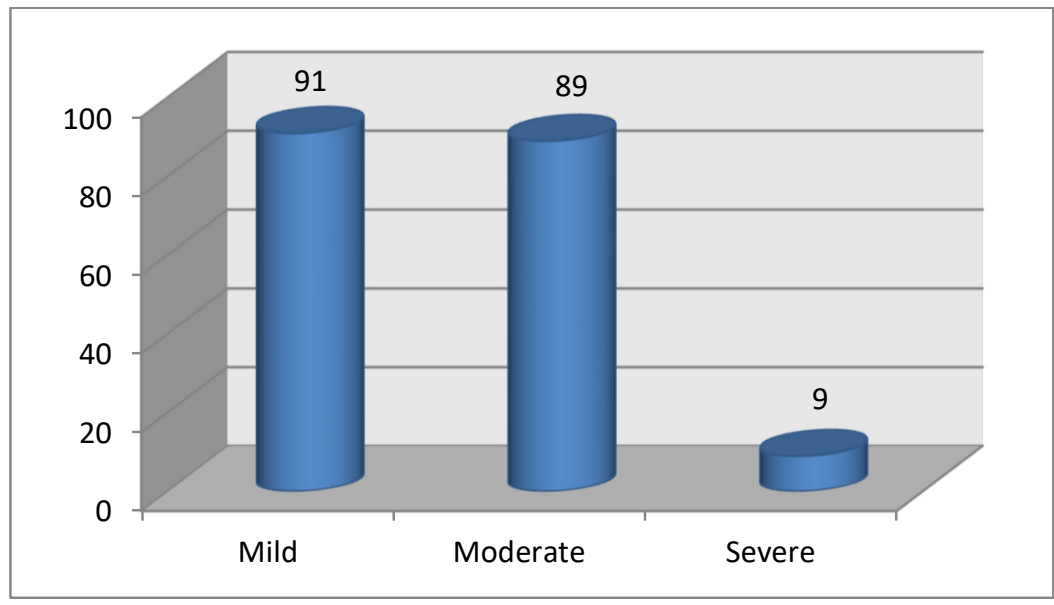

Fig 1: Type of anemia

Out of patients, the most prevalent age group with anemia was found to be $12-<24$ months, followed by $6-<12$ months (fig 2).

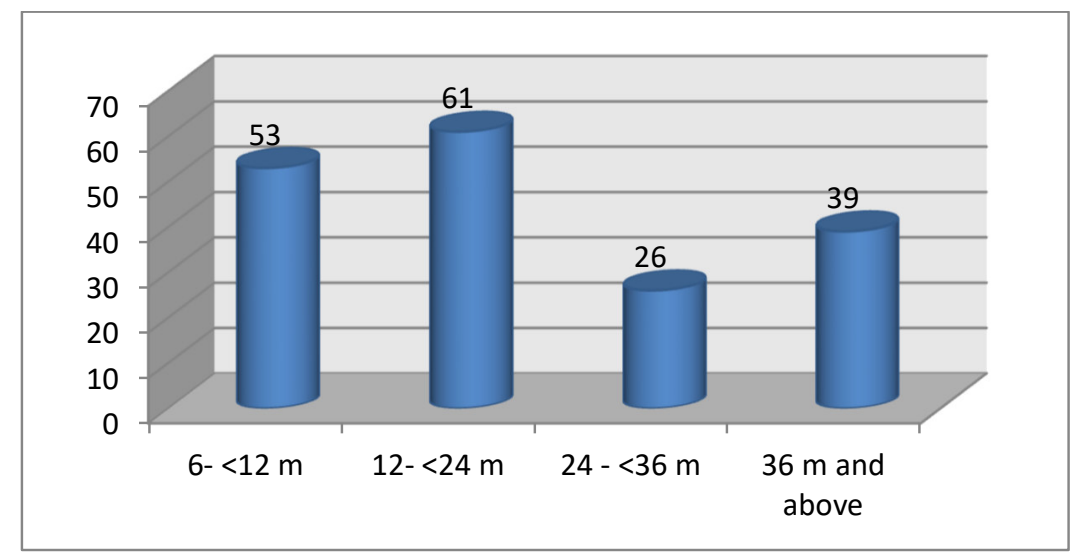

Fig 2: Age wise distribution of anemic patients

The nutritional status of the anemic patients was analysed. It was observed that $48 \%$ of the anemic children were malnourished. Most of them belonged to the weaning phase. Most of the mothers or other care takers of these children 
were uneducated or were educated only upto the primary level. $52.5 \%$ of the children were from poverty ridden area with very low income of the parents (Table: 1).

\section{Table 1: General characteristics of the anemic patients}

\begin{tabular}{|l|l|}
\hline Characteristics & Number (\%) \\
\hline Nutritional status & $86(48.0 \%)^{*}$ \\
Malnourished & $61(34.1 \%)$ \\
Well nourished & $32(17.9 \%)$ \\
Overweight/Obese & \\
\hline Caretaker education & $53(29.6 \%)$ \\
None & $77(43.0 \%)$ \\
Primary & $31(17.3 \%)$ \\
Secondary & $18(10.1 \%)$ \\
College & \\
\hline Financial status & $94(52.5 \%)^{*}$ \\
Low & $34(19.0 \%)$ \\
Middle & $51(28.5 \%)$ \\
High & \\
\hline Weight / age index & $4(2.2 \%)$ \\
$<-2$ z score & $175(97.8 \%)$ \\
$\geq-2$ z score & \\
\hline Height / age index & $7(3.9 \%)$ \\
$<-2$ z score & $172(96.1 \%)$ \\
\hline-2 z score & \\
\hline
\end{tabular}

- $\quad * \mathrm{p}=<0.001$

Of the micronutrients testes, iron deficiency either pure or mixed with other nutrients were the most predominant with folic acid deficiency being the lowest ( Fig 3)

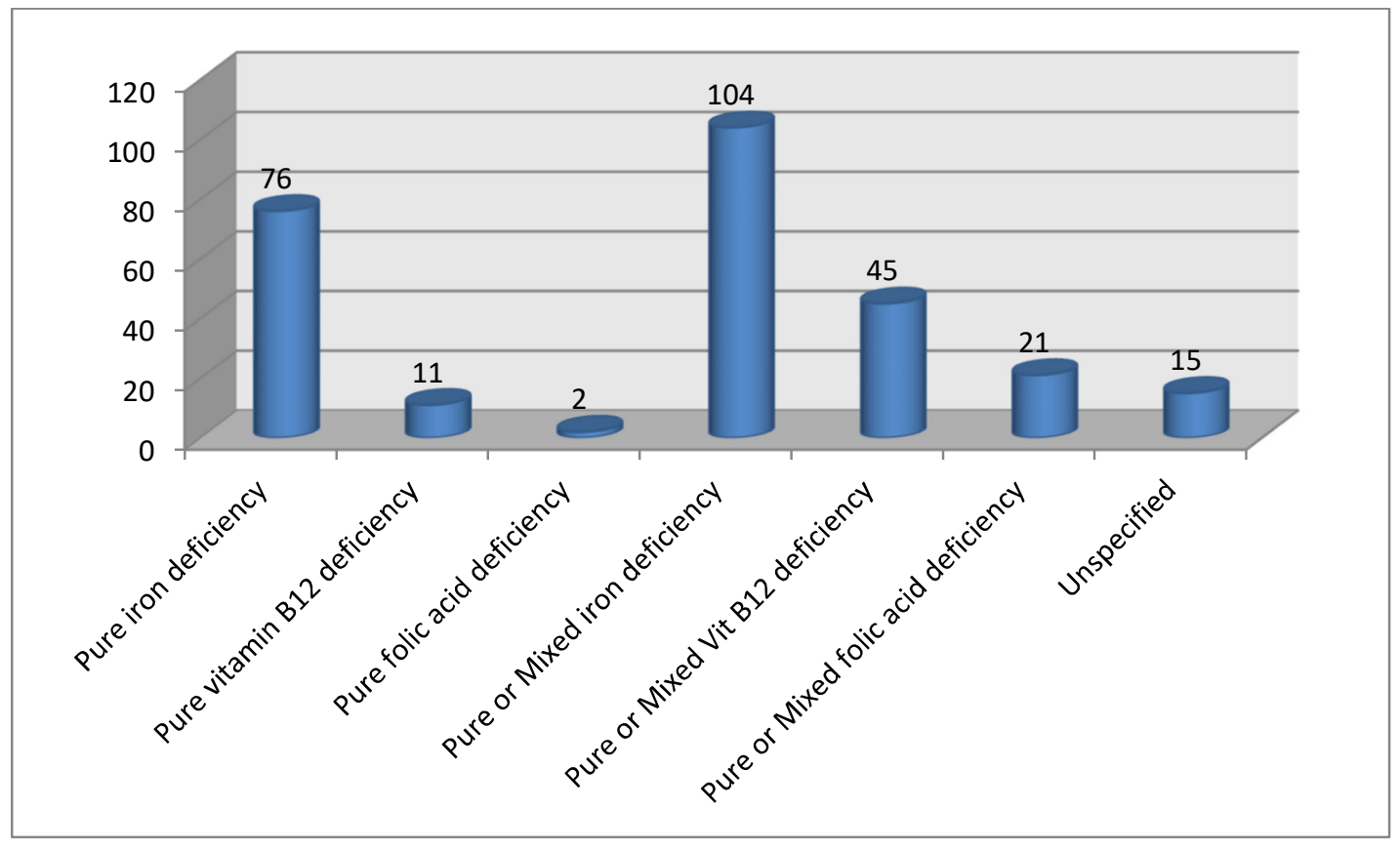

Fig 3: Nutrients deficiency in anemic patients 
$46.4 \%$ of the children had some form of gastrointestinal disorder like diarrhea, abdominal pain etc, $39.7 \%$ with respiratory tract infections including asthma (Table: 2 ) .

Table 2: Diseases associated with anemia.

\begin{tabular}{|l|l|}
\hline Diseases associated & No \\
\hline Gastrointestinal diseases & $83(46.4 \%)^{*}$ \\
\hline Respiratory tract infections & $71(39.7 \%)$ \\
\hline Asthma & $17(9.5 \%)$ \\
\hline Other diseases & $8(4.5 \%)$ \\
\hline
\end{tabular}

- $* \mathrm{p}=<0.001$

\section{Discussion}

Anemia is a major health problem though out the world. In our study a very high prevalence of anemia of $45.7 \%$ among the children who approached our department was observed. This was in concordance to various other studies. $43 \%$ of the children below 5 years of age who were brought to the emergency ward in Zaire were anemic [18]. A slightly lower prevalence of $32.8 \%$ was observed in the state of Pernambuco [19] and 45.1\% in Vietnam [20], while a very high prevalence of 70-79 \% was observed by researchers from Tanzania, Kenya and South Africa [21-23]. In sub-Saharan African countries, prevalence of $82 \%$ in Benin and $83 \%$ in Mali were found [24].

The highest rate of prevalence of anemia occurred in the 12-24 months age group. This could be because of the fact that most mothers, who were from the rural background continued to breast feed the children till more than a year and slowly wean off the child before 2 years of age. This age group was followed by $<12$ months $(29.6 \%)$. Also there is a rapid growth of the child during this phase as a result a greater requirement of iron $[25,26]$

We have not found any significant association of the gender on the prevalence of anemia. While many studies corroborate our study [27, 28], few other researchers have found an association between the two, with boys being more affected than girls[16,29].

In our study, we found $48 \%$ of the children to be malnourished. Several population studies have also found and increasing trend of anemia in malnourished and obese children [19,30]. Although anemia is seen predominantly among the underweight children, it was also found in overweight children This could be due to the lack of intake of minerals and vitamins in adequate quantities. However, no association was found in another study in Brazil [31].
Iron deficiency was found to be the most common etiology for the presence of anemia in children, followed by Viatamin B12 deficiency and folic acid deficiency. The same was reported by Gomber et al in a similar study [32]. Mixed micronutrient deficiency was also found in many of the children. This could be due to the inadequate food intake of the children.

Low intake of iron rich food and diminished nutrient absorption caused by changes in the gastrointestinal system has also contributed to the low iron status of the child [33].

We have found a significant association between the low income level of the family to be one of the contributors for anemia. This could be due to the low purchasing capacity of the family. Similar association have been reported in other studies from other countries $[34,35]$.

\section{Conclusion}

In conclusion, we present an alarming burden of anemia among the children especially those in the 12-24 months age group.

Anemia is a global problem and requires proper understanding of its associated factors, so that effective measures can be taken to combat this disorder. Proper food, rich in nutrients, iron supplements are some of the essential requirements. Regular check ups for the children below 5 years must be conducted to that the effective actions can be taken as early as possible. Proper education on the importance of iron and its harmful effects in the child's mental and physical growth must be emphasized in the population.

Source of Support: Nil, Conflict of Interest: None Permission of IRB: Yes 


\section{References}

1. Verma M, Chhatwal J, Kaur G. Prevalence of anemia among urban school children of Punjab. Indian Pediatr. 1998 Dec;35(12):1181-6.

2. Stoltzfus RJ, Chwaya HM, Tielsch JM, Schulze KJ, Albonico M, Savioli L. Epidemiology of iron deficiency anemia in Zanzibari schoolchildren: the importance of hookworms. Am J Clin Nutr. 1997 Jan;65(1):153-9.

3. Malhotra AK, Srivastava RN. A study on impact of socioeconomic status on haemoglobin levels of rural school children of district Wardha. Indian J Prev Soc Med 1982; 13 : 95-99.

4. Hedberg K, Shaffer N, Davachi F, Hightower A, Lyamba B, Paluku KM, Nguyen-Dinh P, Breman JG. Plasmodium falciparum-associated anemia in children at a large urban hospital in Zaire. Am J Trop Med Hyg. 1993 Mar;48(3):365-71.

5. Premji Z, Hamisi Y, Shiff C, Minjas J, Lubega P, Makwaya C. Anaemia and Plasmodium falciparum infections among young children in an holoendemic area, Bagamoyo, Tanzania. Acta Trop. 1995 Mar;59(1):55-64.

6. World Health Organization Iron deficiency anemia assessment, prevention and control. A guide for programme managers. Geneva; WHO; 2001.

7. Villalpando S, Shamah-Levy T, Ramírez-Silva CI, Mejía-Rodríguez F, Rivera JA. Prevalence of anemia in children 1 to 12 years of age. Results from a nationwide probabilistic survey in Mexico. Salud Publica Mex. 2003;45 Suppl 4:S490-8.

8. DeMaeyer EM, Dallman P, Gurney JM, Hallberg L, Sood SK,vSrikantia SG. Preventing and controlling iron deficiency anaemia through primary health care. Geneva : World Health Organization; 1989 p. 8-9.

9. Fleming AF, Werblińska B. Anaemia in childhood in the guinea savanna of Nigeria. Ann Trop Paediatr. 1982 Dec;2(4):161-73.

10. Greenwood BM, Bradley AK, Greenwood AM, Byass P, Jammeh K, Marsh K, Tulloch S, Oldfield FS, Hayes R. Mortality and morbidity from malaria among children in a rural area of The Gambia, West Africa. Trans R Soc Trop Med Hyg. 1987;81(3):478-86.
11. Rolo S, Morgado M. Anemia: terapêutica farmacológica. Rev de la Ofil. 2006; (16): 34-40

12. Freire WB, Dirren H, Barclay D. Iron deficiency anemia in Ecuador In: Hercberg S, Galan P, Dupin H.Recent knowledge on iron and folate deficiencies in the world. Paris: Collogue INSEAM; 1990. p. 47-54

13. Batista Filho M, Migliolo TC. Alimentação e nutrição no nordeste do Brasil. Recife: Instituto Materno Infantil Professor Fernando Figueira (IMIP); 2006.

14. Dallman PR, Siimes MA, Stekel A. Iron deficiency in infancy and childhood. Am J Clin Nutr. 1980 Jan;33(1):86-118.

15. Torres MA, Sato K, Queiroz Sde S. [Anemia in children under 2 years in basic health care units in the State of São Paulo, Brazil]. Rev Saude Publica. 1994 Aug;28(4):290-4.

16. WHO Multicentre Growth Reference Study Group, WHO Child Growth Standards: Length/Heightfor-Age, Weight-for-Age, Weight-for-Length, Weightfor-Height and Body Mass Index-for-Age: Methods and Development, Geneva, Switzerland, 2006.

17. DeMaeyer E, Adiels-Tegman M. The prevalence of anaemia in the world. World Health Stat Q. 1985;38(3):302-16.

18. Molyneux ME, 1995. The clinical manifestations and diagnosis of malaria. Pasvol G, ed. Malaria. Baillieres Clinical Infectious Diseases. Volume 2. London: Bailliere Tindall, 271-292.

19. Leal LP, Batista Filho M, Lira PI, Figueiroa JN, Osório MM. Prevalence of anemia and associated factors in children aged 6-59 months in Pernambuco, Northeastern Brazil. Rev Saude Publica. 2011 Jun;45(3):457-66.

20. Nguyen PH, Nguyen KC, Le Mai B, Nguyen TV, Ha KH, Bern C, Flores R, Martorell R. Risk factors for anemia in Vietnam. Southeast Asian J Trop Med Public Health. 2006 Nov;37(6):1213-23.

21. Magesa AS, Magesa PM. Association between anaemia and infections (HIV, malaria and hookworm) among children admitted at Muhimbili National Hospital. East Afr J Public Health. 2012 Sep;9(3):96100. 
22. Foote EM, Sullivan KM, Ruth LJ, Oremo J, Sadumah I, Williams TN, Suchdev PS. Determinants of anemia among preschool children in rural, western Kenya. Am J Trop Med Hyg. 2013 Apr;88(4):757-64. doi: 10.4269/ajtmh.12-0560. Epub 2013 Feb 4.

23. Heckman J, Samie A, Bessong $P$, Ntsieni $M$, Hamandi H, Kohler M, Milam B, Scriver J, Dillingham R. Anaemia among clinically well under-fives attending a community health centre in Venda, Limpopo Province. S Afr Med J. 2010 Jul 5;100(7):445-8.

24. Kikafunda JK, Lukwago FB, Turyashemererwa F. Anaemia and associated factors among under-fives and their mothers in Bushenyi district, Western Uganda. Public Health Nutr. 2009 Dec;12(12):2302-8. doi: 10.1017/S1368980009005333. Epub 2009 Apr 6.

25. Monteiro CA, Szarfarc SC, Mondini L. [Secular trends in childhood in the city of São Paulo, Brazil (1984-1996)]. Rev Saude Publica. 2000 Dec;34(6 Suppl):62-72.

26. Rocha DS, Lamounier JÁ, Capanema FD, Franceschini SC, Norton RC, Costa AB, et al. Estado nutricional e prevalência de anemia em crianças que frequentam creches em Belo Horizonte, Minas Gerais.Rev Paul Pediatr. 2008; 26(1): 6-13.

27. Neuman NA, Tanaka OY, Szarfarc SC, Guimarães PR, Victora CG. [Prevalence and risk factors for anemia in Southern Brazil]. Rev Saude Publica. 2000 Feb;34(1):56-63.

28. Gomber S, Kumar S, Rusia U, Gupta P, Agarwal KN, Sharma S. Prevalence \& etiology of nutritional anaemias in early childhood in an urban slum. Indian $\mathrm{J}$ Med Res. 1998 Jun;107:269-73.
29. Agho KE, Dibley MJ, D'Este C, Gibberd R. Factors associated with haemoglobin concentration among Timor-Leste children aged 6-59 months. J Health Popul Nutr. 2008 Jun;26(2):200-9.

30. Mamiro PS, Kolsteren P, Roberfroid D, Tatala S, Opsomer AS, Van Camp JH. Feeding practices and factors contributing to wasting, stunting, and irondeficiency anaemia among 3-23 month old children in Kilosa district, rural Tanzania. J Health Popul Nutr. 2005;23(3):222-30.

31. Tympa-Psirropoulou E, Vagenas C, Dafni O, Matala A, Skopouli F. Environmental risk factors for iron defi ciency anemia in children 12-24 months old in the area of Thessalia in Greece. Hippokratia. 2008;12(4):240-50.

32. Ngnie-Teta I, Receveur O, Kuate-Defo B. Risk factors for moderate to severe anemia among children in Benin and Mali: insights from a multilevel analysis. Food Nutr Bull. 2007 Mar;28(1):76-89.

33. Silva LS, Giuglian ER, Aerts DR. [Prevalence and risk factors for anemia among children in Brazil]. Rev Saude Publica. 2001 Feb;35(1):66-73.

34. Oliveira RS, Diniz Ad Ada S, Benigna MJ, Miranda-Silva SM, Lola MM, Goncalves MC, AsciuttiMoura L, Rivera MA, Santos LM. [Magnitude, geographic distribution and trends of anemia in preschoolers, Brazil]. Rev Saude Publica. 2002 Feb;36(1):26-32.

35. Batista Filho M, Rissin A. [Nutritional transition in Brazil: geographic and temporal trends]. Cad Saude Publica. 2003;19 Suppl 1:S181-91. Epub 2003 Jul 21.

\section{How to cite this article?}

Yeluri SK. Prevalence of anemia and its etiology: a study in a semi urban area: Int J Pediatr Res 2016;3(4):266271.doi:10.17511/ijpr.2016.i04.11. 